Website: https://ojs.unikom.ac.id/index.php/common

DOI Jurnal: https://doi.org/10.34010/common

DOI Artikel: https://doi.org/10.34010/common.v5i1.4033

\title{
MOTIF DAN KEPUASAN MAHASISWA ILMU KOMUNIKASI UNJ ANGKATAN 2019 DALAM MENGGUNAKAN MEDIA SOSIAL INSTAGRAM
}

\author{
Tasya Indah Firdausi ${ }^{1}$, K. Y.S. Putri ${ }^{2}$ \\ Program Studi Ilmu Komunikasi, Fakultas Ilmu Sosial, Universitas Negeri Jakarta, J1. R.Mangun Muka Raya, \\ RT.11/RW.14, Rawamangun, Kec. Pulo Gadung, Kota Jakarta Timur, Daerah Khusus Ibukota Jakarta 13220, \\ Indonesia $^{1,2}$ \\ E-mail: \\ TasyaIndahFirdausi_1410619067@mhs.unj.ac.id ${ }^{1}$ \\ kinkinsubarsa@unj.ac.id ${ }^{2}$
}

\begin{abstract}
Social media has various types and of course, has different functions and ways of working. Someone uses social media, of course, because there is something they are looking for (motive), and everyone has different motives for using social media, and this is influenced by 4 indicators, namely, information, social interactionl, entertainment, and personal identity. Instagram is a place where you can easily share photos, videos, and interact with other people through online networks. This study uses a quantitative approach with 45 samples and uses a random sampling technique. The data was collected by distributing questionnaires in the form of google form. The data analysis technique used was coding (Likert scale), testing the validity and reliability using SPSS version 21, and calculating the average (mean). From the results obtained, it shows that the motive of information is the motive most sought by students in using Instagram, social satisfaction is the highest satisfaction obtained by students in using Instagram. And the value of the biggest gap between motive and satisfaction is the information indicator.
\end{abstract}

Keywords: social media, Instagram, motives, satisfaction, discrepancy

\begin{abstract}
Abstrak
Media sosial memiliki jenis yang beragam dan tentunya memiliki fungsi dan cara kerja yang berbeda-beda. Seseorang menggunakan media sosial tentunya karena ada sesuatu yang dicari (motif), dan setiap orang memiliki motif menggunakan media sosial yang berbeda-beda, dan hal itu dipengaruhi oleh 4 indikator, yaitu, informasi, interaksi sosial, hiburan, dan identitas pribadi. Instagram adalah tempat dimana dapat berbagi foto, video, dan berinteraksi dengan orang lain melalui jejaring online dengan mudah. Penelitian ini menggunakan pendekatan kuantitatif dengan 45 sampel dan menggunakan teknik random sampling. Pengumpulan data dilakukan dengan menyebar kuesioner berupa google form. Teknik analisis data yang dilakukan adalah pemberian kode (skala likert), uji validitas dan reliabilitas menggunakan SPSS versi 21, dan menghitung rata-rata (mean). Dari hasil yang didapat menunjukkan motif informasi merupakan motif yang paling dicari mahasiswa dalam menggunakan Instagram, kepuasan informasi merupakan kepuasan yang paling tinggi didapatkan mahasiswa dalam menggunakan Instagram. Dan nilai kesenjangan terbesar antara motif dan kepuasan yaitu dari indikator hiburan.
\end{abstract}

Kata Kunci: media sosial, Instagram, motif, kepuasan, kesenjangan 
Website: https://ojs.unikom.ac.id/index.php/common

DOI Jurnal: https://doi.org/10.34010/common

DOI Artikel: https://doi.org/10.34010/common.v5i1.4033

\section{Pendahuluan}

\subsection{Latar Belakang}

Perkembangan teknologi khususnya internet, masyarakat dimudahkan dalam berbagai bidang di kehidupan sehari-hari. Internet dimanfaatkan masyarakat sebagai media untuk membantu kegiatan sehari-hari seperti untuk bekerja, berbisnis, belajar, hingga mengisi waktu luang. Perkembangan teknologi dan internet ini pun memaksa masyarakat untuk ikut berperan aktif agar tidak gaptek (gagap teknologi). Karena perkembangan internet ini tentunya memiliki segi positif, yaitu memudahkan penyampaian dan penyebaran informasi secara cepat. (Soliha et al., 2019). Salah satu platform digital yang memanfaatkan internet yaitu media sosial. Media Sosial berisi konten-konten online yang mudah diakses dimanapun, kapanpun yang dibuat menggunakan teknologi penerbitan. Dari teknologi inilah terjadi pergeseran cara mencari informasi, berita, orang, dan lain sebagainya (Prihatiningsih, 2017).

Fungsi media sosial yang semakin beragam membuat penggunanya setiap tahun bertambah. Berikut adalah data pengguna media sosial di Indonesia di tahun 2020 menurut Hootsuite We are social dalam data reportal.

\section{Gambar 1. Pengguna media sosial di Indonesia} tahun 2020

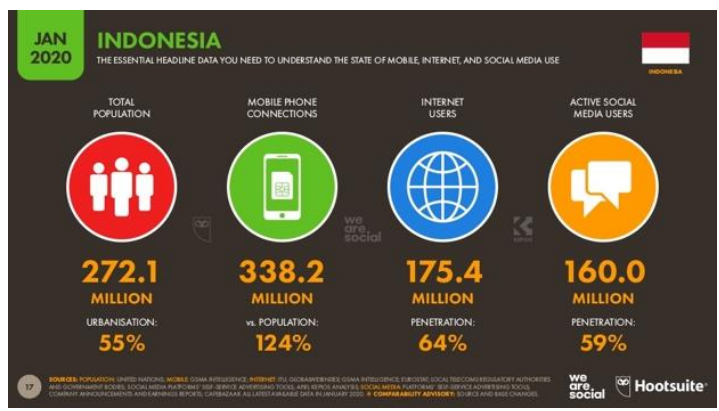

Sumber: We Are Social \& Hootsuite, 2020 diakses 5 November 2020
Dari data tersebut terlihat pengguna media sosial di Indonesia lebih dari setengah total populasinya, yaitu sebesar $59 \%$ dari total penduduk. Ini membuktikan bahwa pengguna media sosial di Indonesia mengalami peningkatan yang cukup signifikan.

Media sosial tidak memandang umur, dari anak kecil hingga orang dewasa dapat menggunakanya. Berikut pengguna media sosial di Indonesia tahun 2020 berdasarkan umur menurut Hootsuite We are social dalam data reportal.

Gambar 2. Pengguna media sosial di Indonesia tahun 2020 berdasarkan umur

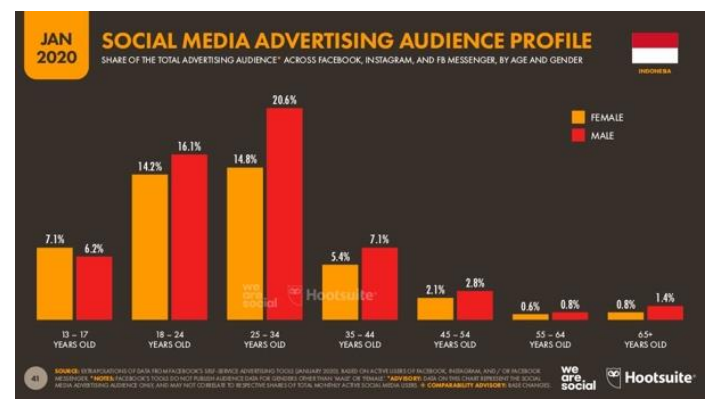

Sumber: We Are Social \& Hootsuite, 2020 diakses 5 November 2020

Berdasarkan data tersebut, pengguna media sosial didominasi oleh kalangan anak muda, dan yang paling banyak di rentang umur 23-34 tahun. Menurut Lukes dalam Mukhtar, Putri, dkk 2020, saat ini sedang trend jejaring online menggunakan media sosial di kalangan anak muda. Media sosial telah mengubah cara berpikir, cara berkomunikasi dengan kerabat, teman, keluarga, dan norma budaya. (Mukhtar et al., 2020).

Seseorang menggunakan media sosial tentunya karena ada sesuatu yang dicari (motif), dan setiap orang memiliki motif menggunakan media sosial yang berbedabeda, dan hal itu dipengaruhi oleh 4 indikator, yaitu, informasi, interaksi sosial, hiburan, dan identitas pribadi. Motif ini bergantung dari kegunaan atau fungsi media itu sendiri dan tingkat kepuasam yang diperoleh dalam menggunakannya (Sari et al., 2019). 
Website: https://ojs.unikom.ac.id/index.php/common

DOI Jurnal: https://doi.org/10.34010/common

DOI Artikel: https://doi.org/10.34010/common.v5i1.4033

Salah satu media sosial yang sering dan banyak digunakan adalah Instagram. Instagram adalah tempat dimana dapat berbagi foto, video, dan berinteraksi dengan orang lain melalui jejaring online dengan mudah. (Budiargo, 2015: 48). Instagram sendiri dirilis pada Oktober 2010 dengan pendirinya yaitu Kevin Systrom dan Mike Krieger. Dengan foto maupun video yang diunggah di Instagram, orang lain dapat memberikan reaksi dengan memberikan like dan komentar pada unggahan tersebut. Singkatnya, Instagram merupakan media yang dapat membagikan dan memperoleh informasi, berinteraksi dengan orang lain, sebagai media bisnis maupun promosi, dan menemukan teman baru (e (Puspitorini, 2016).

Dengan fasilitas dan kemudahan yang ditawarkan Instagram banyak pengguna memanfaatkan Instagram sebagai sumber informasi, tempat berinteraksi dengan orang lain, media promosi, mencari hiburan, dan membentuk identitas pribadi.

Berikut adalah pengguna Instagaram di Indonesia tahun 2020.

\section{Gambar 3. Pengguna Instagram di Indonesia tahun 2020}

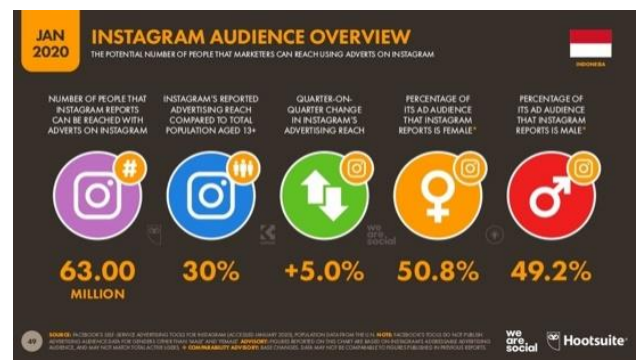

Sumber: We Are Social \& Hootsuite, 2020 diakses 5 November 2020

Berdasarkan dari data tersebut pengguna Instagram di Indonesia sebanyak 63 juta orang, dimana pengguna perempuan lebih banyak yaitu sebesar $50.8 \%$, sedangkan pengguna laki-laki sebesar 49.2\%. Karena tergolong media sosial yang mudah diakses dan mempunyai beragam kegunaan inilah yang membuat masyarakat menggunakan Instagram untuk membantu melakukan pekerjaan atau aktivitas sehari-harinya.

Para pengguna tentunya memiliki maksud dalam menggunakan Instagram, ada motif dan kepuasan yang ingin diperoleh ketika menggunakan media sosial Instagram. Baik itu untuk mencari atau membagikan informasi, berinteraksi dengan sesama, mencari hiburan, dan menjadi platform untuk memberitahu identitas pribadi mereka. Apa motif mereka menggunakan Instagram dan kepuasan apa yang ingin diperoleh dari menggunakan Instagram.

\subsection{Rumusan Masalah}

Bagaimana penggunaan Instagram pada mahasiswa Ilmu Komunikasi UNJ angkatan 2019 ?

\subsection{Tujuan Penelitian}

Tujuan penelitian ini adalah untuk menjawab rumusan masalah yaitu melihat bagaimana penggunaan Instagram pada mahasiswa Ilmu Komunikasi UNJ angkatan 2019.

\section{Kajian Pustaka dan Kerangka Pemikiran}

\subsection{Media Sosial}

Media yang memanfaatkan penggunaan internet salah satunya adalah media sosial. Menurut Arianti dalam Soliha (2019) dengan teknologi berbasis mobile dan web, media sosial membuat komunikasi berubah menjadi dialog yang interaktif (Soliha et al., 2019). Karena media sosial memfasilitasi untuk dapat saling berinterkasi maka masyarakat banyak yang menggunakannya untuk media berkomunikasi (Nathania \& Rusdi, 2018). Dengan teknologi yang sangat mudah digunakan dan diakses membuat adanya pergeseran cara mendapatkan informasi atau 
Website: https://ojs.unikom.ac.id/index.php/common

DOI Jurnal: https://doi.org/10.34010/common

DOI Artikel: https://doi.org/10.34010/common.v5i1.4033

konten, mencari tahu seseorang, membagikan dan membuat berita, dan lain sebagainya. (Prihatiningsih, 2017)

Media sosial adalah sebuah media online yang diakses dengan menggunakan internet yang dapat membagikan konten atau informasi, seperti data, profil, dan kegiatan penggunanya, dan dapat sebagai media berinteraksi dengan sesama tanpa adanya batasan waktu dan lokasi. Dengan media sosial dapat membangun maupun mengembangkan hubungan antarpersonal. Aktivitas, profil yang dibagikan di media sosial dapat membuat para penggunanya saling berkomunikasi dengan saling memberikan like maupun komentar pada gambar, video, dan status yang diunggah di media sosial. (Puspitorini, 2016)

\subsection{Instagram}

Instagram merupakan salah satu aplikasi media sosial dengan kegunaan yang dapat digunakan untuk memberikan efek pada foto, mengambil foto atau gambar, dan membagikannya. Smartphone menjadi perangkat yang diarahkan dalam penggunaan Instagram. (Innova, 2016)

Instagram adalah jejaring sosial yang dapat digunakan sebagai media untuk membagikan informasi, berinteraksi atau berkomunikasi dengan orang lain, dan bisa mengenal lebih dalam dengan para pengguna lain dari video maupun foto yang diunggah di Instagram. Konten yang berupa foto maupun video yang diunggah di Instagram dapat tersimpan sehingga dapat dilihat kembali kedepannya sebagai kenangan. Dengan membagikan konten di media sosial Instagram, mereka menginginkan umpan balik dari para followers atau pengikutnya berupa komentar dan like dari konten yang diunggahnya. (Puspitorini, 2016)

Menurut Ma'ruf dan Moh.Ali dalam Nathania (2018), dengan kegunaannya sebagai sarana informasi, media sosial Instagram banyak dimanfaatkan untuk berbagai macam hal seperti, media bisnis yaitu online shop, akun penyedia jasa, akun resmi suatu instansi resmi maupun tidak, dan akun hiburan (Nathania \& Rusdi, 2018).

\subsection{Teori Uses and Gratification}

Penelitian ini menggunakan teori Uses and Gratification. Menurut Richard dan Lynn dalam Soliha 2019, teori Uses and Gratification berasumsi bahwa pengguna media berusaha memenuhi kebutuhannya. Karena pada kebanyakan orang, mereka menggunakan media untuk memenuhi kebutuhannya dan mencari kepuasan (Soliha et al., 2019). Sesuai dengan pernyataan West dan Turner dalam Nathania dan Rusdi 2018, para pengguna media secara aktif mencari media tertentu, isi dan kegunaan media tersebut untuk memenuhi kebutuhan atau menghasilkan kepuasan tertentu (Nathania \& Rusdi, 2018).

Teori Uses and Gratifications ini menjelaskan bahwa media dianggap berupaya memenuhi motif dari khalayak atau penggunanya. Jika motif terpenuhi maka kebutuhan penggunaknya terpenenuhi. Dengan demikian media yang seperti itu disebut sebagai media yang efektif (Bekti, 2018).

Motif atau Kepuasan yang diharapkan (Gratification Sought) merupakan motif yang menjadi alasan sesorang menggunakan media. Motif adalah dorongan atau motivasi dalam diri manusia karena kebutuhan yang harus dipenuhi. Motivasi atau dorongan ini yang menyebabkan manusia bertingkah laku melakukan sesuatu. Hal ini lah yang mendorong seseorang menggunakan media karena untuk mendapatkan kebutuhan atau kepuasan di media (Innova, 2016).

Setiap orang memiliki motif menggunakan media yang berbeda-beda, dan hal itu dipengaruhi oleh 4 indikator yang membentuk motif, yaitu, informasi, interaksi sosial, hiburan, dan identitas pribadi (Sari et al., 2019). 
Website: https://ojs.unikom.ac.id/index.php/common

DOI Jurnal: https://doi.org/10.34010/common

DOI Artikel: https://doi.org/10.34010/common.v5i1.4033

Kepuasan yang diperoleh (Gratification Obtained) adalah kepuasan yang didapatkan setelah seseorang menggunakan suatu media. Dan hal khusus apa saja yang diperoleh setelah menggunakan media (Innova, 2016).

Dalam teori Uses and Gratification juga dapat dilihat tingkat kesenjangan antara motif dan kepuasan dari hasil mean atau rata-rata dari GS (motif) dan GO (kepuasan), jika ratarata GS lebih besar dari GO maka ini berarti media tersebut telah memeneuhi kebutuhan penggunanya (Bekti, 2018).

Konsep dari teori Uses and Gratification menyatakan apakah motif terpenuhi oleh media, dan apakah penggunanya merasa puas menggunakan media. (Nathania \& Rusdi, 2018). Kegunaan media dan tingkat kepuasan dalam menggunkan media juga mempengaruhi motif seseorang. Karena kebutuhan setiap orang yang berbeda-beda maka media digunakan sebagai pemenuhan kebutuhan dan kepuasan yang berbeda-beda pula. Menurut McQuail (1987), hal ini berarti penyebab seseorang menggunakan media karena dipengaruhi oleh masalah psikologis maupun lingkungan sosialnya, oleh karena itu mereka menggunakan media untuk menangani masalah tersebut atau sebagai pemuas kebutuhan (Innova, 2016).

\section{Obek dan Metode Penelitian}

Paradigma penelitian ini adalah positivisme. Paradigma positivisme menggunakan penalaran deduktif untuk mengedepankan teori yang dapat diuji melalui desain penelitian yang telah ditentukan oleh peneliti sebelumnya dan bersifat objektif (Sekaran \& Bougie, 2016).

Penelitian ini menggunakan pendekatan kuantitatif. Menurut Kriyantono dalam Sari (2019), tujuan pendekatan kuantitatif adalah untuk menggambarkan suartu masalah atau peristiwa yang dapat disimpulkan (Sari et al., 2019).
Metode yang digunakan adalah metode survei deskriptif. Penggunaan metode survei deskriptif yaitu untuk mendeskripsikan populasi yang sedang diteliti dengan menggunakan kuisioner (Kriyantono dalam Bekti, 2018).

Populasi penelitian ini adalah mahasiswa Ilmu Komunikasi UNJ angkatan 2019 yang mempunyai akun dan menggunakan Instagram. Penentuan sampel penelitian dengan menggunakan rumus Slovin.

\section{Rumus slovin:}

$$
\mathrm{n}=\frac{N}{1+N(e)^{2}}
$$

Keterangan:

$$
\begin{aligned}
& n=\text { ukuran sampel } \\
& \mathrm{N}=\text { ukuran populasi } \\
& \mathrm{e}=\text { batas toleransi kesalahan } \\
& (10 \%)
\end{aligned}
$$

Sampel penelitian menggunakan rumus Slovin:

$$
n=\frac{81}{1+81(0,01)^{2}}
$$

$\mathrm{n}=44.75$, dibulatkan menjadi 45 .

Jadi untuk ukuran sampel penelitian ini adalah 45 dari total populasi 81 mahasiswa Ilmu Komunikasi UNJ angkatan 2019.

Teknik penarikan sampel yang digunakan adalah teknik acak sederhana (simple random sampling) dimana sampel yang diambil dari populasi seacara acak tanpa memperhatikan tingkatan atau strata (Sari et al., 2019).

Penelitian ini menggunakan 2 variabel, yaitu variabel $\mathrm{X}$ dan variabel $\mathrm{Y}$. Untuk variabel $\mathrm{X}$ nya adalah Motif (Gratification Sought) dan variabel Y nya kepuasan yang diperoleh (Gratification Obtained).

Pengumpulan data dilakukan dengan menyebaran kuesioner dalam bentuk google 
Website: https://ojs.unikom.ac.id/index.php/common

DOI Jurnal: https://doi.org/10.34010/common

DOI Artikel: https://doi.org/10.34010/common.v5i1.4033

form yang disebarkan menggunakan media sosial. Teknik analisis data dengan pemberian kode, uji validitas, uji reliabilitas, dan menghitung mean atau rata-rata.

\section{Pemberian Kode (Skala Likert)}

Pemberian kode menggunakan skala likert. Skala likert digunakan untuk mengukur tingkat setuju dan tidak setujunya responden mengenai suatu pernyataan yang berhubungan dengan suatu kejadian atau peristiwa (Kuncoro dalam Innova, 2016). Dalam penelitian ini pernyataan responden mengenai variabel motif dan kepuasan diukur dengan skor satu sampai empat. Setiap skor ini memiliki penilaian yang berbeda-beda yaitu, untuk skor:

1: Sangat Tidak Setuju

2: Tidak Setuju

3: Ragu-ragu

4: Setuju

5: Sangat Setuju

2. Uji Validitas

Menurut Siregar dalam Imron (2019) validitas menilai sejauh mana alat ukur yang digunakan mampu mengukur apa yang ingin di ukur (Imron, 2019). Uji validitas dilakukan dengan menggunakan SPSS versi 21.

3. Uji Reliabilitas

Menurut Muhidin dan Abdurahman dalam Imron (2019) reliabilitas menujukkan bahwa suatu instrumen sebagai alat ukur akurat dan konsisten sehingga hasil dari suatu pengukuran dapat meyakinkan atau dipercaya (Imron, 2019). Uji reliabilitas dilakukan dengan menggunakan SPSS versi 21.

4. Mean (nilai rata-rata)

Mean atau nilai rata-rata adalah nilai tengah dari jumlah bilangan. Dalam penelitian ini skor mean dilihat mana yang paling tinggi dan yang paling rendah dalam frekuensi, agar mengetahui indikator apa dari motif dan kepuasan yang paling menonjol dalam penggunaan media sosial Instagram (Innova, 2016). Nilai mean juga digunakan untuk menghitung kesenjangan antara motif dan kepuasan.

\section{Hasil dan Pembahasan}

\subsection{Uji Validitas}

Uji validitas penelitian ini menggunakan metode KMO and bartletts's test.

Tabel 1. Validitas Variable X (Motif)

KMO and Bartlett's Test

\begin{tabular}{|c|c|c|}
\hline \multirow{2}{*}{\multicolumn{2}{|c|}{$\begin{array}{l}\text { Kaiser-Meyer-Olkin Measure of Sampling } \\
\text { Adequacy. }\end{array}$}} & .713 \\
\hline & & \\
\hline \multirow{5}{*}{$\begin{array}{l}\text { Bartlett's Test of } \\
\text { Sphericity }\end{array}$} & Approx. Chi- & 152.019 \\
\hline & Square & \\
\hline & & 28 \\
\hline & dt & \\
\hline & Sig. & .000 \\
\hline
\end{tabular}

Berdasarkan uji validitas dengan menggunakan metode KMO and Bartlett's Test menunjukkan nilai KMO variable $X$ (motif) sebesar 0.713 dimana melebihi 0.5, maka variable $\mathrm{X}$ (Motif) penelitian ini valid.

Tabel 2. Validitas Variable Y (Kepuasan)

KMO and Bartlett's Test

\begin{tabular}{|c|c|c|}
\hline \multirow{2}{*}{\multicolumn{2}{|c|}{$\begin{array}{l}\text { Kaiser-Meyer-Olkin Measure of Sampling } \\
\text { Adequacy. }\end{array}$}} & .693 \\
\hline & & \\
\hline \multirow{4}{*}{$\begin{array}{l}\text { Bartlett's Test of } \\
\text { Sphericity }\end{array}$} & Approx. Chi- & 167.180 \\
\hline & Square & \\
\hline & $\mathrm{df}$ & 28 \\
\hline & Sig. & .000 \\
\hline
\end{tabular}

Berdasarkan uji validitas dengan menggunakan metode KMO and Bartlett's Test menunjukkan nilai KMO variable $\mathrm{Y}$ 
(Kepuasan) sebesar 0.693 dimana melebihi 0.5 , maka variable Y (Kepuasan) penelitian ini valid.

\subsection{Uji reliabilitas}

Uji reliabilitas pada penelitian ini menggunakan metode Alpha.

Tabel 3. Reliabilitas Variabel X (Motif)

Reliability Statistics

\begin{tabular}{|r|r|}
\hline $\begin{array}{l}\text { Cronbach's } \\
\text { Alpha }\end{array}$ & N of Items \\
\hline .843 & 8 \\
\hline
\end{tabular}

Dari hasil tersebut menujukkan bahwa nilai Cronbach's Alpha variable motif sebesar 0.843 melebihi 0.6, maka data variabel motif penelitian ini reliabel.

Table 4. Reliabilitas Variabel Y (Kepuasan)

Reliability Statistics

\begin{tabular}{|r|r|}
\hline $\begin{array}{l}\text { Cronbach's } \\
\text { Alpha }\end{array}$ & N of Items \\
\hline .855 & 8 \\
\hline
\end{tabular}

Dari hasil tersebut menujukkan bahwa nilai Cronbach's Alpha variable kepuasan sebesar 0.855 melebihi 0.6, maka data variable kepuasan penelitian ini reliabel.

\subsection{Komponen Variabel Motif}

Tabel 5. Rata-rata dari Variabel Motif (Gratification Sought)

\begin{tabular}{|c|c|c|c|}
\hline Variabel & Indikator & Mean & Peringkat \\
\hline Motif & Informasi & 4.34 & 1 \\
\cline { 2 - 4 } & $\begin{array}{c}\text { Interaksi } \\
\text { Sosial }\end{array}$ & 4.15 & 3 \\
\cline { 2 - 4 } & Hiburan & 4.30 & 2 \\
\hline
\end{tabular}

\begin{tabular}{|l|c|c|c|}
\hline & $\begin{array}{c}\text { Identitas } \\
\text { Pribadi }\end{array}$ & 4.04 & 4 \\
\hline
\end{tabular}

Berdasarkan data pada tabel tersebut menujukkan rata-rata indikator motif informasi sebesar 4.34 yang mana merupakan nilai rata-rata indikator motif tertinggi dari keempat indikator. Diikuti peringkat kedua adalah indikator hiburan sebesar 4.30, selanjutnya peringkat ketiga yaitu indikator interaksi sosial dengan nilai mean sebesar 4.15 , dan peringkat terakhir adalah indikator identitas pribadi dengan nilai mean sebesar 4.05.

\subsection{Komponen Variabel Kepuasan}

Tabel 6. Rata-rata dari Variabel Kepuasan (Gratification Obtained)

\begin{tabular}{|c|c|c|c|}
\hline Variabel & Indikator & Mean & Peringkat \\
\hline Kepuasan & Informasi & 4.32 & 1 \\
\cline { 2 - 4 } & $\begin{array}{c}\text { Interaksi } \\
\text { Sosial }\end{array}$ & 4.28 & 2 \\
\cline { 2 - 4 } & Hiburan & 4.21 & 3 \\
\cline { 2 - 4 } & $\begin{array}{c}\text { Identitas } \\
\text { Pribadi }\end{array}$ & 4.03 & 4 \\
\hline
\end{tabular}

Berdasarkan dari tabel tersebut menujukkan rata-rata indikator informasi sebesar 4.32 yang mana merupakan nilai ratarata indikator kepuasan tertinggi dari keempat indikator. Diikuti peringkat kedua adalah indikator interaksi sosial sebesar 4.28, selanjutnya peringkat ketiga yaitu indikator hiburan dengan nilai mean sebesar 4.21, dan peringkat terakhir adalah indikator identitas pribadi dengan nilai mean sebesar 4.03. 
Website: https://ojs.unikom.ac.id/index.php/common

DOI Jurnal: https://doi.org/10.34010/common

DOI Artikel: https://doi.org/10.34010/common.v5i1.4033

\subsection{Kesenjangan Motif dan Kepuasan}

Tabel 5. Kesenjangan Motif dan Kepuasan

\begin{tabular}{|c|c|c|c|}
\hline Indikator & $\begin{array}{c}\text { Motif } \\
(\mathrm{GS})\end{array}$ & $\begin{array}{c}\text { Kepuasan } \\
(\mathrm{GO})\end{array}$ & $\begin{array}{c}\text { Kesenjangan } \\
(\mathrm{GS}-\mathrm{GO})\end{array}$ \\
\hline Informasi & 4.34 & 4.32 & 0.02 \\
\hline $\begin{array}{c}\text { Interaksi } \\
\text { Sosial }\end{array}$ & 4.15 & 4.28 & -0.13 \\
\hline Hiburan & 4.30 & 4.21 & 0.09 \\
\hline $\begin{array}{c}\text { Identitas } \\
\text { Pribadi }\end{array}$ & 4.03 & 4.04 & -0.01 \\
\hline $\begin{array}{c}\text { Rata-rata } \\
\text { Variabel }\end{array}$ & $\mathbf{4 . 2 5}$ & $\mathbf{4 . 2 1}$ & \\
\hline
\end{tabular}

Menurut Kriyantono dalam Soliha (2019), nilai kesenjangan yang semakin besar menandakan semakin media tidak memuaskan penggunanya. Sedangkan jika semakin kecil nilai kesenjangan yang didapatkan maka semakin puas penggnanya menggunakan media (Soliha et al., 2019).

Berdasar data pada tabel.5 menunjukkan bahwa rata-rata variabel motif lebih besar dari rata-rata variabel kepuasan. Ini menunjukkan bahwa kepuasan yang diperoleh mahasiswa Ilmu Komunikasi UNJ Angkatan 2019 dalam menggunakan Instagram tidak sepenuhnya terpenuhi. Seperti dari kesenjangan indikator hiburan sebesar 0.09 yang merupakan kesenjangan tertinggi karena nilai mean variabel kepuasan pada indikator hiburan sebesar 4.21 yang mana nilai tersebut lebih kecil dari nilai mean variabel motif 4.30. Diikuti indikator informasi dengan nilai kesenjangan sebesar 0.02 dan indikator identitas pribadi sebesar -0.01. Untuk kesenjangan paling rendah adalah indikator interaksi sosial yaitu sebesar -0.09 , ini menunjukkan bahwa indikator interaksi sosial paling memuaskan diantara keempat indikator tersebut.
Kesenjangan indikator hiburan merupakan indikator yang paling besar kesenjangannya, maka ini berarti banyak dari mahasiswa Ilmu Komunikasi UNJ angkatan 2019 yang kepuasan hiburan tidak terpenuhi, hal ini dapat disebabkan oleh beberapa faktor seperti, adanya media sosial lain yang digunakan untuk mencari hiburan, dan lebih sering menggunakan instagram untuk kebutuhan informasi, identitas pribadi dan berinteraksi dengan orang lain.

\section{Kesimpulan dan Rekomendasi}

\subsection{Kesimpulan}

Motif dan kepuasan menggunakan Instagram terdiri dari 4 indikator yaitu informasi, interaksi sosial, hiburan, dan identitas pribadi.

1. Motif pada indikator informasi merupakan motif dengan nilai mean tertinggi diantara keempat indikator yaitu sebesar 4.34. Motif pada indikator identitas pribadi merupakan motif dengan nilai mean terendah yaitu sebesar 4.05.

2. Kepuasan pada indikator informasi merupakan kepuasan dengan nilai mean tertinggi diantara keempat indikator yaitu sebesar 4.32. Kepuasan pada indikator identitas pribadi merupakan kepuasan dengan nilai mean terendah yaitu sebesar 4.03 .

3. Nilai kesenjangan yang diperoleh dari pengurangan nilai rata-rata motif (GS) dan kepuasan (GO) menunjukkan kesenjangan dengan nilai terkecil pada indikator identitas pribadi yaitu sebesar -0.13 maka ini berarti media sosial Instagram memuaskan mereka sebagai media berinteraksi sosial dengan pengguna lainnya.

4. Kesenjangan dengan nilai terbesar pada indikator hiburan yaitu sebesar 0.09 maka ini berarti banyak dari mahasiswa Ilmu Komunikasi UNJ angkatan 2019 yang 
Website: https://ojs.unikom.ac.id/index.php/common

DOI Jurnal: https://doi.org/10.34010/common

DOI Artikel: https://doi.org/10.34010/common.v5i1.4033

kepuasan hiburan tidak terpenuhi, hal ini dapat disebabkan oleh beberapa faktor seperti, adanya media sosial lain yang digunakan untuk mencari hiburan dan lebih sering menggunakan instagram untuk kebutuhan informasi, identitas pribadi dan berinteraksi dengan orang lain.

\subsection{Rekomendasi}

Dalam memenuhi kebutuhan di media sosial Instagram, harus dilakukan dengan bijak dan tepat, beberapa rekomendasi dalam menggunakan Instagram:

1. Berbagai informasi dapat disebarkan di Instagram, oleh karena itu tidak boleh menyebarkan informasi yang tidak benar atau hoax.

2. Harus tetap waspada atau berhati-hati jika berkenalan dengan orang baru di media sosial Instagram.

3. Agar terhindar dari kejahatan di dunia maya, pengguna tidak boleh menyebarkan data yang bersifat pribadi.

4. Memperhatikan tutur bahasa atau etika ketika mengeluarkan pendapat di media sosial.

\section{Daftar Pustaka}

Bekti, B. K. 2018. "Motif dan Kepuasan Menggunakan Jejaring Sosial Instagram (Studi Kesenjangan Antara Motif Dan Kepuasan Mahasiswa Ilmu Komunikasi Universitas Muhammadiyah Surakarta Terhadap Akun Instagram @ umsurakarta)", Skripsi Ilmu Komunikasi. Surakarta: Fakultas Komunikasi dan Informatika Universitas Muhammadiyah Surakarta.

Imron, I. (2019). "Analisa Pengaruh Kualitas Produk Terhadap Kepuasan Konsumen Menggunakan Metode Kuantitatif Pada CV.Meubele Berkah Tangerang", dalam
Indonesian Journal on Software Engineering (IJSE) Volume 5 No 1, halaman: 19-28.

Innova, E. I. (2016). "Motif dan Kepuasan Pengguna Instagram di Komunitas Instameet Indonesia", dalam Jurnal EKomunikasi Volume 4 No 1, halaman: 111.

Mukhtar, S., Putri, K. Y. S., Larasati, M., Sary, dkk. 2020. "Digital Social Media: Creative Economy Quarantine during the Coronavirus Pandemic, 2020", dalam IJICC Volume 13 No 7, halaman: 416430.

Nathania, \& Rusdi, F. 2018. "Studi Kesenjangan Motif dan Kepuasan Followers dalam Mengikuti Akun @ tmcpoldametro di Instagram", dalam Koneksi Volume 2 No 2, halaman: 486492.

Prihatiningsih, W. 2017. "Motif Penggunaan Media Sosial Instagram Di Kalangan Remaja", dalam Jurnal Communication Volume 8 No 1, halaman: 51-65

Puspitorini, D. A. 2016. "Motif dan Kepuasan Penggunaan Instagram (Studi Kesenjangan antaraa Motif dan Kepuasan Penggunaan Media Sosial Instagram pada Mahasiswa Universitas Muhammadiyah Surakarta Angkatan 2013)", Skripsi Ilmu Komunikasi. Surakarta: Fakultas Komunikasi dan Informatika Universitas Muhammadiyah Surakarta.

Sari, N. A., Bukhari, Usman, dkk. 2019. "Hubungan Motif dan Kepuasan Penggunaan Media Sosial Instagram di Mahasiswa Komunikasi Penyiaran Islam Angkatan 2014-2017", dalam AL MUNIR: Jurnal Komunikasi Dan Penyiaran Islam Volume 10 No 2, halaman 74-78. 
Website: https://ojs.unikom.ac.id/index.php/common

DOI Jurnal: https://doi.org/10.34010/common

DOI Artikel: https://doi.org/10.34010/common.v5i1.4033

Sekaran, U., \& Bougie, R. 2016. Research Methods for Business A Skill-Building Approach (7th ed.). Chichester: John Wiley \& Sons Ltd.

Soliha, P. H., D, S., \& Abdullah, A. (2019). "Tingkat Kepuasan Pemanfaatan Grup Media Sosial Whatsapp Bagi Mahasiswa Ilmu Komunikasi Uin Suska Riau", dalam Jurnal Riset Mahasiswa Dakwah Dan Komunikasi (JRMDK) Volume 1 No 4, halaman 248-254.

We Are Social \& Hootsuite. 2020. "Digital 2020: Indonesia", dalam https://datareportal.com/reports/digital2020-indonesia diakses 5 November 2020. 